\title{
Learning Theories and Cultural Intelligence (CQ): a Literature Review Study and Mapping of CQ Development Method
}

\author{
Nur Arief Rahmatsyah PUTRANTO ${ }^{*}$ * \\ Aurik GUSTOMO2 \\ Anggara WISESA ${ }^{3}$
}

DOI: $10.24818 / \mathrm{mer} / 2022.02-06$

\begin{abstract}
The emerging of globalization makes the importance of cultural intelligence (CQ) acknowledged both by researchers and practitioners. Therefore, many researchers have their focus on how to develop someone's CQ. Although there have been many studies related to methods to develop $C Q$, but there are still few related to learning theories. whereas learning theories should become references when talking about teaching or developing someone including the development of CQ. Moreover, there is still limited research that tried to map or compare the method used to develop someone's CQ. This paper will try to fill that gap. The paper used systematical literature review of papers related to $C Q$ development. From the review, it was found that the method to develop someone $C Q$ can be categories into traditional class, direct experiential, and indirect experiential. From the mapping process of the $C Q$ development method into these categories, it is known that most of previous research focuses on using direct experiential learning process. However, there is no research of $C Q$ development that combine the direct experiential and indirect experiential as well as combination of the three categories. Through those findings, this paper suggests some possibilities for further research that can benefit both the body of knowledge and people who want to develop $C Q$.
\end{abstract}

KEYWORDS: cultural intelligence $(C Q)$, direct experiential, indirect experiential, learning theories, traditional class.

JEL CLASSIFICATION: $I 20, M 16$

\section{INTRODUCTION}

The emergence of the era of globalization has made it important for a person to have good intercultural skills. With good intercultural skills, a person will easily interact and cooperate with people from other countries who have different unique cultures. One of the essential intercultural skills is cultural intelligence (CQ), a type of intelligence that explains why a person can adapt and work well with people from different cultures (Ang et al., 2007; Thomas, 2006; Thomas et al., 2008). The benefits of having a high CQ on one's effectiveness in interacting in environments with different cultures have been recognized by both academicians and practitioners (Clawson, 2019; Fang, Schei, \& Selart, 2018; Marr, 2019). Based on this, much research has been done to find out how CQ can be developed. This CQ development process cannot be separated from the learning process.

\footnotetext{
1* Corresponding author, School of Business and Management, Institut Teknologi Bandung, Indonesia, nur.arief@sbm-itb.ac.id

${ }^{2}$ School of Business and Management, Institut Teknologi Bandung, Indonesia

${ }^{3}$ School of Business and Management, Institut Teknologi Bandung, Indonesia
} 
In the process of developing $\mathrm{CQ}$, many researchers already tried a different method. For example, Rehg et al. (2012) using traditional approaches which are lecturing class using powerpoint to develop CQ of 110 military and government civilians. Meanwhile, MacNab et al. (2012) developed an experiential approach to develop CQ. Bücker and Korzilius (2015) also tried to develop students CQ using the Ecotonos simulation game. However, even though a lot of researchers talked about how to develop CQ, very little relate the process with learning theories even though it focus the process on how people learn something. Learning is an essential process for humans by which an individual gains new knowledge that can help their lives. To get optimal results, one must understand what kind of learning method is suitable. With the right learning method, a person will absorb the knowledge well and develop to the fullest.

The learning process is a complex process involving the individual capability to process information and interpersonal skills that consider planned and conditional variables (Nygaard, Højlt \& Hermansen, 2008). The learning process is affected by internal and external interaction (Illeris, 2009). External interaction refers to the interaction between an individual and its environment, while internal interaction means the acquisition of knowledge itself that involves learning content and incentive function (Illeris, 2009). When talking about learning content, the individual tries to understand something that involves knowledge, skills, opinion, insight, and other processes to create meaning and the ability to face problems that lead to the individual's functionality (Illeris, 2009). At the same time, incentive refers to mental energy that someone gives to a learning process that involves emotion, motivation, and volition to achieve mental balance and develop sensitivity (Illeris, 2009). These two dimensions interact, trigger the learning process, and help individuals integrate with society and develop their sociability (Illeris, 2009).

It becomes clear that the CQ development process is somehow related to learning theory. However, research that tried to link CQ development and learning theories is still limited. This may be caused by the fact that there is some field that has not been explored related to the CQ development process. From that, this paper took initiative to review the method used to develop CQ by previous research and look at them from the perspective of some of learning theories. The review result will then be a guidance in mapping the CQ development method to learning categories. This mapping may be beneficial for both for further research and implementation of CQ development. From this mapping, the categorization of the CQ development method is expected to emerge, which can help further research to understand and explore more about the CQ development process. The mapping and categorization will also help any party that wants to replicate, use, or develop methods in developing someone's CQ.

\section{LITERATURE REVIEW}

There are many learning theories ranging from andragogy to problem-based learning (Minter, 2011). However, this research will focus on cognitive theories, experiential learning, and gamification learning, which are considered relevant to the CQ development process.

Unlike behavior learning theories that emphasize the learner's reaction to a particular treatment, cognitive learning theories focus on how learners construct new knowledge based on pre-existing knowledge (Şanal et al., 2019). Cognitive learning theories talk about the mental process in acquiring, structuring, and creating knowledge (Kay \& Kibble, 2016; Şanal, et al., 2019). These theories try to explain how the mind processes information to knowledge. 
One of the fundamentals of cognitive theories is constructivism. Constructivism sees that knowledge is a construction of people's minds, which means that people are not just passive receivers of knowledge, but also active in constructing and creating knowledge (Walat, 2014). The assumption of constructivism in cognitive theories is that learners can create knowledge by adjusting their existing knowledge (Şanal et al., 2019). The activity to build knowledge can vary, such as using verbal, practical, intellectual, sensory, receptive, and emotional (Walat, 2014). Another vital method in implementing cognitive theories is giving feedback to learners; thus, they can learn from their mistakes and create new knowledge from the mistake (Şanal et al., 2019). Therefore, it is essential to note that in the cognitive theories approach, the assessment not only assesses the knowledge given but also assesses whether the learner can implement the knowledge in different situations or contexts (Şanal et al., 2019). To facilitate the process, an educator must not act as a source of knowledge; rather, they must act as mediators and facilitators that support learners in a learning process (Walat, 2014).

Meanwhile, experiential learning focuses on how people can learn through experience (Kolb, 1984, p. 41). It has six main foundations, which are (1) Focus on a process, not outcomes; (2) Learning is a re-learning process; (3) Learning is the result of conflict resolution; (4) Learning is an integrated function of adaptation; (5) Learning is a process of interaction between individual and its environment; and (6) Learning is a process of creating and not transmitting knowledge (Kolb \& Kolb, 2009). Experiential learning focuses on transforming experience into knowledge; therefore, in its learning cycle, it is based on four stages which are: (1) concrete experiences; (2) reflective observation; (3) abstract conceptualization; and (4) active experimentation (Kolb \& Kolb, 2009).

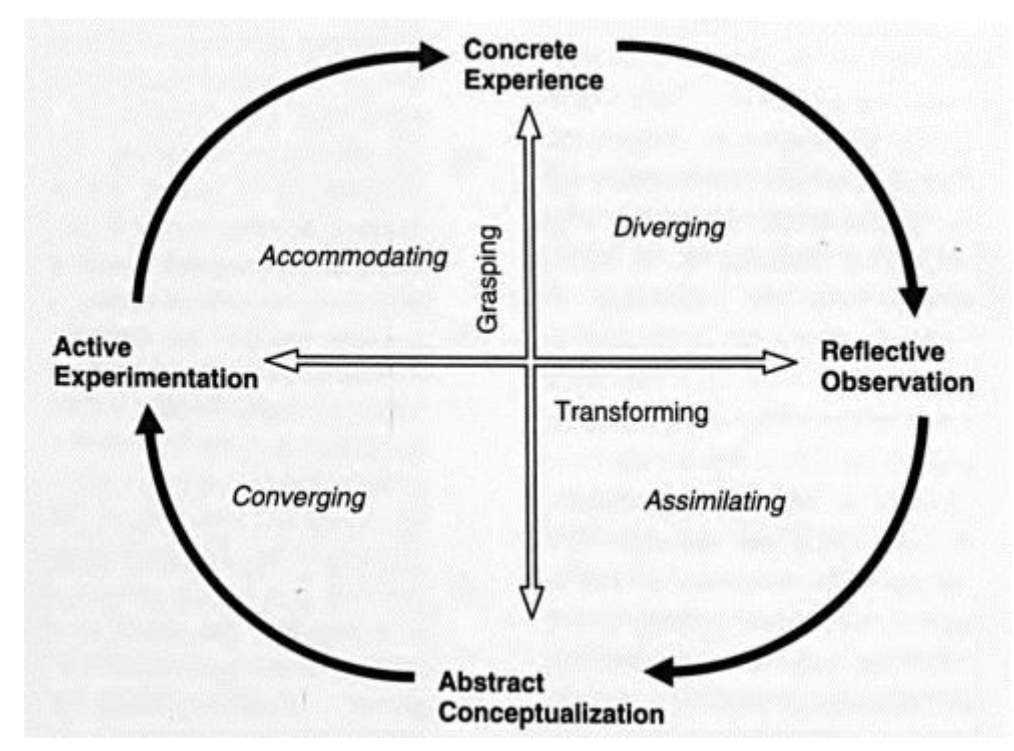

Figure 1. Experiential learning cycle

Source: adapted from Kolb \& Kolb (2009, p. 44)

The different learners' responses toward this cycle result in four types of learning styles. The first is convergent, which emphasizes abstract conceptualization and active experimentation, which puts someone stronger in implementing the theories or ideas (Kolb \& Kolb, 2009). The second is accommodating, which combines active experimentation and concrete experience, which make them able to learn from an action or experiment (Kolb \& Kolb, 2009). The third learning style is known as diverging, in which people who are dominant in concrete experience and reflective observation can thus reflect, evaluate, and generate ideas about an 
event from a different perspective (Kolb \& Kolb, 2009). The latter is assimilating, in which people have a strong point in reflective observation and abstract conceptualization that result in the ability to put various information into a logical concept (Kolb \& Kolb, 2009).

A different approach from cognitive and experiential learning, gamification learning, is a process that uses game elements or mechanics in a non-game situation (Al-Azawi et al., 2016). Gamification learning focuses not only on finding the methods that make students understand the material and achieve the learning objectives, but also on how students can feel motivated and engage with the learning process (Cheong et al., 2014).

Based on the definition, it is essential to learn about the game elements when talking about gamification. The game elements are any features that indicate the game's characteristics ranging from concrete elements that can be seen in a game, such as a leaderboard, to abstract elements such as enduring play (Cheong et al., 2014). These game elements cannot be separated when people use gamification in a learning context. Some researchers have shown the importance of the game elements in conducting research about gamification. For example, the research conducted by Ault and colleagues focused on rapid and competitive play, timed performance, immediate feedback, and high rates of response (Ault et al., 2015). Meanwhile, other researchers used a combination of levels, points, badges, virtual goods, and a leaderboard to create a framework regarding the effectiveness of social gamification (Simões et al., 2013). Align with that; there is also research that tried to use role-play elements in the education process that include experience point, RPG classes, event encounter, and reward system (Ntokos, 2019). Finally, Toda and colleagues proposed the dimension of game elements that incorporate performance, ecological, social, personal, and fictional (Toda, et al., 2019). These examples showed that the game elements are one of the most important aspects to be considered when trying to implement gamification. These elements have also been tried to be used in developing CQ, such as in simulation, role-play, or avatar method (Bücker \& Korzilius, 2015; Fischer, 2011; Kirste \& Holtbrügge, 2019).

In addition, gamification also shows favorable results regarding its effectiveness in the learning process. Regarding the learning process, the most visible effect of gamification is the increased level of students enagement (Chen, 2020; Khaleel et al., 2020; Sun \& Hsieh, 2018). Aligned with that, the implementation of gamification also showed a positive effect on learners' motivation (Bicen \& Aydogan, 2020; Gómez-Carrasco et al., 2019; Sun \& Hsieh, 2018). Moreover, gamification can also increase learners' attention (Sun \& Hsieh, 2018). Related to knowledge, using gamification can increase the participants' mastery and retention of knowledge (Chen, Lu \& Lien, 2019; Putz et al., 2020). In addition to that, gamification can also positively affect learners' skills and competencies, such as communication and argumentation skills (Bicen \& Aydogan, 2020; Chen et al., 2019; Tsai et al., 2019).

Looking back on the CQ development process, some researchers use learning theory to develop a method to improve someone's CQ. For example, the lecturing approach, as an embodiment of cognitive theory, is used to develop CQ (Bobanovic \& Grzinic, 2019; Rehg et al., 2012), or MacNab (2012) who developed a framework of experiential learning for CQ development that consists of seven stages which are (1) awareness development of CQ and cultural differences; (2) giving instruction to participants about experiential learning; (3) checking participants status prior to the experience; (4) experiencing cross-culture environment; (5) internalizing the experience; (6) getting feedback from the instructor; and (7) having a group discussion and social sharing with other participants (MacNab, 2012). Additionally, the CQ development process that used Ecotonos aligned with gamification learning has also been done (Bücker \& Korzilius, 2015). 


\section{RESEARCH METHODOLOGY}

To map the previous research regarding the CQ development process, the first thing to be done is to search the literature related to the CQ development process. In doing this, the researcher used the ProQuest database because it combines several databases. Therefore, it is considered that ProQuest has comprehensive coverage regarding literature review on the CQ development process.

In order to find the relevant literature, some keywords are generated. There are five keywords used in this search process that are considered to have high relevance to the topic of CQ development. These keywords are 'Cultural Intelligence'; 'Development'; 'Training'; 'Education'; and 'Improving'. To get optimum results, those keywords are combined into a single keyword, which is ('Cultural Intelligence') AND ('Development' OR 'Training' OR 'Education' OR 'Improving'). By using this keyword, the search engine will find literature related to CQ development, CQ training, CQ education, and CQ improvement, which is the terminology used by previous research to the process in developing CQ.

From the search, 2,434 literatures match the keywords. After finding the literature, the following process is the screening process. The screening process is needed to filter all the literature to get the literature that matches the objective of this research. There are several steps in the screening process. First, the literature must be a research article or scholarly journal written in English. This screening is used to guarantee the quality of the literature and make it easier for a researcher to read and understand the content of the paper. The following screening process is to find the literature that focuses on cultural intelligence context so it will avoid literature that has other variables as their research object to be included in this research. Finally, from those journal papers, the screening process is done to find a paper that focuses on developing someone's CQ. After conducting the screening process, there are 39 articles of literature that are considered relevant to the $\mathrm{CQ}$ development process.

After finding these articles, the researcher conducted a review with a focus on the method in developing CQ. From this review, the categorization and mapping were made, which will be discussed in subsequent sections.

\section{RESEARCH RESULTS AND DISCUSSIONS}

In order to be able to map the method in developing CQ, the review was conducted on 39 papers. The review focuses on identifying what methods the previous researcher used (or considered capable of developing a CQ) to develop someone's CQ. The result of this review can be seen in Table 1 .

Table 1. Method in Developing CQ

\begin{tabular}{|c|l|l|}
\hline No & \multicolumn{1}{|c|}{ Author(s) } & \multicolumn{1}{c|}{ How CQ is developed } \\
\hline 1 & Gertsen \& Søderberg (2010) & Expatriate assignment \\
\hline 2 & Fischer (2011) & Lecture and simulation game \\
\hline 3 & MacNab et al. (2012) & Experiential training \\
\hline 4 & MacNab \& Worthley (2012) & Experiential training \\
\hline 5 & Rehg et al. (2012) & Lecturing class using powerpoint \\
\hline 6 & MacNab (2012) & Experiential training \\
\hline 7 & Eisenberg et al. (2013) & Lecturing and study abroad \\
\hline
\end{tabular}




\begin{tabular}{|c|c|c|}
\hline No & Author(s) & How CQ is developed \\
\hline 8 & Erez et al. (2013) & International project \\
\hline 9 & Rosenblatt et al. (2013) & $\begin{array}{l}\text { Lecturing class and interaction with people } \\
\text { from different culture }\end{array}$ \\
\hline 10 & Taras et al. (2013) & International project \\
\hline 11 & Goerlich (2014) & Lecturing, case study, and role plays \\
\hline 12 & Sahin et al. (2014) & International assignment \\
\hline 13 & Buchtel (2014) & Traditional class \\
\hline 14 & Tuleja (2014) & cross-cultural immersion \\
\hline 15 & Stewart et al. (2014) & International service programs \\
\hline 16 & Reichard et al. (2014) & $\begin{array}{l}\text { Two-hour } \\
\text { training sessions }\end{array}$ \\
\hline 17 & Wood \& St. Peters (2014) & Short-term cross-cultural study tours \\
\hline 18 & Varela \& Gatlin-Watts (2014) & International student exchange program \\
\hline 19 & Bücker \& Korzilius (2015) & Simulation game \\
\hline 20 & Reichard et al. (2015) & $\begin{array}{l}\text { International assignment and classroom } \\
\text { training }\end{array}$ \\
\hline 21 & Ko et al. (2015) & The global link project \\
\hline 22 & McRae et al. (2016) & Canadian-European exchange program \\
\hline 23 & Kurpis \& Hunter (2016) & $\begin{array}{l}\text { Classroom and interview international } \\
\text { students }\end{array}$ \\
\hline 24 & Mayer et al. (2016) & $\begin{array}{l}\text { Intercultural competence training course } \\
\text { (theoretical study, group discussions, } \\
\text { individual reflections,case study analysis } \\
\text { and the development of best practices) }\end{array}$ \\
\hline 25 & Ramsey \& Lorenz (2016) & $\begin{array}{l}\text { Classroom (the use of a text book and } \\
\text { current event discussions) }\end{array}$ \\
\hline 26 & McClinton \& Schaub (2017) & $\begin{array}{l}\text { Class training (traditional lecture, } \\
\text { homework/reading assignments, } \\
\text { presentations, panel discussions, and } \\
\text { journaling) }\end{array}$ \\
\hline 27 & Chao et al.n(2017) & International exchange program \\
\hline 28 & Presbitero \& Toledano (2017) & $\begin{array}{l}\text { Cross-cultural training (Lecturing, role } \\
\text { playing, and case study) }\end{array}$ \\
\hline 29 & Young et al. (2018) & Mentoring refugee \\
\hline 30 & Gustomo et al. (2018) & Short field trip \\
\hline 31 & Sheetal et al. (2018) & Reciprocal mentoring \\
\hline 32 & Bengoa et al. (2018) & Classroom and international project \\
\hline 33 & Alexandra (2018a) & Experiential cross-cultural training \\
\hline 34 & Alexandra (2018b) & Experiential cross-cultural training \\
\hline 35 & Azevedo \& Shane (2019) & Classroom and team project \\
\hline 36 & Bobanovic \& Grzinic (2019) & $\begin{array}{l}\text { Lecturing, reading literature, sharing } \\
\text { session, game, role-play, and focus group } \\
\text { discussion }\end{array}$ \\
\hline 37 & Kirste \& Holtbrügge (2019) & Simulation with digital avatar \\
\hline 38 & Pierce \& Longo (2019) & Classroom \\
\hline 39 & Stoian $(2020)$ & Case studies, discussions and simulations \\
\hline
\end{tabular}


From Table 1, it is known that the methods that are used in developing CQ vary, ranging from classroom to using a digital avatar. To map those methods, first the categories need to be created. The categories must be general, so they can become references in mapping the method. After analyzing the methods, three categories emerge, which are 'Traditional Class', 'Direct Experiential', and 'Indirect Experiential'. The traditional class is a category that accommodates traditional methods such as lecturing, reading a book, presenting, or watching movies. In contrast, the direct experiential category involves methods that allow participants to interact with other people from different countries. The indirect experiential category is where participants can still experience the interaction with other people from different countries without directly interacting, such as using simulation or role-play.

After deciding the category, the mapping is done based on these categories. The result of the mapping can be seen in Table 2 .

Table 2. Categorization of Methods in Developing CQ

\begin{tabular}{|c|l|l|}
\hline No & \multicolumn{1}{|c|}{ Author(s) } & \multicolumn{1}{c|}{ Category } \\
\hline 1 & Gertsen \& Søderberg (2010) & Direct experiential \\
\hline 2 & Fischer (2011) & Traditional class and Indirect experiential \\
\hline 3 & MacNab et al. (2012) & Direct experiential \\
\hline 4 & MacNab \& Worthley (2012) & Direct experiential \\
\hline 5 & Rehg et al. (2012) & Traditional class \\
\hline 6 & MacNab (2012) & Direct experiential \\
\hline 7 & Eisenberg et al. (2013) & Traditional class and Direct experiential \\
\hline 8 & Erez et al. (2013) & Direct experiential \\
\hline 9 & Rosenblatt et al. (2013) & Traditional class and Direct experiential \\
\hline 10 & Taras et al. (2013) & Direct experiential \\
\hline 11 & Goerlich (2014) & Traditional class and Indirect experiential \\
\hline 12 & Sahin et al. (2014) & Direct experiential \\
\hline 13 & Buchtel (2014) & Traditional class \\
\hline 14 & Tuleja (2014) & Direct experiential \\
\hline 15 & Stewart et al. (2014) & Direct experiential \\
\hline 16 & Reichard et al. (2014) & Traditional class \\
\hline 17 & Wood \& St. Peters (2014) & Direct experiential \\
\hline 18 & Varela \& Gatlin-Watts (2014) & Direct experiential \\
\hline 19 & Bücker \& Korzilius (2015) & Indirect experiential \\
\hline 20 & Reichard et al. (2015) & Traditional class and Direct experiential \\
\hline 21 & Ko et al. (2015) & Direct experiential \\
\hline 22 & McRae et al. (2016) & Direct experiential \\
\hline 23 & Kurpis \& Hunter (2016) & Traditional class and Direct experiential \\
\hline 24 & Mayer et al. (2016) & Traditional class \\
\hline 25 & Ramsey \& Lorenz (2016) & Traditional class \\
\hline 26 & McClinton \& Schaub (2017) & Traditional class \\
\hline 27 & Chao et al. (2017) & Direct experiential \\
\hline 28 & Presbitero \& Toledano (2017) & Traditional class and Indirect experiential \\
\hline 29 & Young et al. (2018) & Direct experiential \\
\hline 30 & Gustomo et al. (2018) & Direct experiential \\
\hline 31 & Sheetal et al. (2018) & Direct experiential \\
\hline 32 & Bengoa et al. (2018) & Traditional class and Direct experiential \\
\hline
\end{tabular}




\begin{tabular}{|c|l|l|}
\hline No & \multicolumn{1}{|c|}{ Author(s) } & \multicolumn{1}{c|}{ Category } \\
\hline 33 & Alexandra, (2018a) & Direct experiential \\
\hline 34 & Alexandra, (2018b) & Direct experiential \\
\hline 35 & Azevedo \& Shane (2019) & Traditional class and Direct experiential \\
\hline 36 & Bobanovic \& Grzinic (2019) & Traditional class and Indirect experiential \\
\hline 37 & Kirste \& Holtbrügge (2019) & Indirect experiential \\
\hline 38 & Pierce \& Longo (2019) & Traditional class \\
\hline 39 & Stoian (2020) & Traditional class and Indirect experiential \\
\hline
\end{tabular}

Based on Table 2, it can be seen that there is research that used a method that belongs to one category only, while several other researchers used a method that belongs to more than one category. The summary of categorization can be seen in Table 3 .

Table 3. Summary of Categorization

\begin{tabular}{|c|l|c|}
\hline No & \multicolumn{1}{|c|}{ Category } & Number of research \\
\hline 1 & Traditional class & 7 \\
\hline 2 & Direct experiential & 19 \\
\hline 3 & Indirect experiential & 6 \\
\hline 4 & Traditional class and Direct experiential & 5 \\
\hline 5 & $\begin{array}{l}\text { Traditional class and Indirect } \\
\text { experiential }\end{array}$ & 0 \\
\hline 6 & $\begin{array}{l}\text { Direct experiential and Indirect } \\
\text { experiential }\end{array}$ & 0 \\
\hline 7 & $\begin{array}{l}\text { Traditional class, Direct experiential, } \\
\text { and Indirect experiential }\end{array}$ & 2 \\
\hline
\end{tabular}

From Table 3, it can be observed that the most used method is direct experiential. This is probably because CQ does not only talk about cognitive aspects, but also behavioral aspects. Therefore, the use of direct experiential is considered capable of significantly increasing CQ. Meanwhile, the use of indirect experiential is still minimal. This is probably because the direct experiential is considered better than the indirect experiential. In indirect interaction, a person will only feel an imitation of the actual interaction in which there may be discrepancies (e.g. differences in body language). In addition, there are differences in atmosphere and mindset (for example, in indirect learning, people are not too serious because they know that this is only an imitation), which may affect the effectiveness of the learning process. This might also be the reason why there are no studies that combine the use of direct and indirect experiential.

Then, several other studies focused on using traditional classes, possibly because they focused on developing the cognitive aspects of CQ. The exciting thing is that the use of traditional classes is often combined with the use of direct experiential or indirect experiential. This is likely because researchers want to improve cognitive abilities first, and then participants can implement it into behavioral forms. This way, it is expected to give more improvement in CQ development. However, even though there is a combination of traditional class and either direct experiential or indirect experiential, no studies combine these three categories.

This opens up many possibilities for further research related to CQ development. Researchers can further explore indirect experiential learning because it is still limited. The use of indirect experiential can be beneficial mainly because it is possible to create simulations that can represent direct experience with the development of technology. This can also be useful because providing direct experience interacting with people from other countries sometimes 
requires a large amount of money (e.g. conducting study trips abroad), which may not be possible to conduct in several cases.

Another possible research is combining indirect and direct experiential learning. Participants can try indirect experiential learning before directly interacting with people from a different culture.

Finally, combining all categories may lead to exciting research. Researchers can explore how each method can complement each other or compare the effectiveness of each category toward the development of CQ (or toward each dimension of CQ). In that way, people can have more perspective if they want to use a method in developing CQ, whether they want to combine it between categories or use it separately.

\section{CONCLUSIONS}

The importance of CQ makes many researchers research CQ development. However, little is related to learning theories even though learning theory is the basis in people development of people. This paper attempts to understand the method that previous researchers used using cognitive learning theory, experiential learning theory, and gamification learning theory. From that it can be seen that the method for developing someone's CQ can be classified into three categories. Those categores are traditional class which is traditional learning methods such as lecturing, reading a book, presenting, or watching movies, direct experiential which is involving methods that allow participants to interact with other people from different countries, and indirect experiential where participants can still experience the interaction with other people from different countries without directly interacting, such as using simulation or role-play.

From the mapping of the previous method towards toward these categories it is known that most of the previous research using direct experiential learning while the other categories and combination of categories is still limited. From that, there are some further research suggestions to explore more about how to develop CQ. First, research on the indirect experiential method can be explored, as the number is still limited. Second, the CQ development method research that combines both the direct and indirect experiential methods can be done. Finally, research that combines all categories to see how each method complements each other in developing CQ can be carried out or each method of understanding how it affects CQ and its dimension can be compared

By doing research in those aspects, it is expected both academicians and practitioners of CQ will get more understanding in how developing $\mathrm{CQ}$, how each learning process complement each other, and which learning process is suitable to use.

\section{REFERENCES}

Alabassi, D. (2018). Exploring Teachers Perspectives towards Using Gamification Techniques in Online Learning. TOJET: The Turkish Online Journal of Educational Technology, 17(2), 34-45.

Al-Azawi, R., Al-Faliti, F., \& Al-Blushi, M. (2016). Educational Gamification Vs. Game Based Learning: Comparative Study. International Journal of Innovation, Management and Technology, 7(4), 132-136. doi:10.18178/ijimt.2016.7.4.659 
Alexandra, V. (2018a). Predicting CQ development in the context of experiential crosscultural training: The role of social dominance orientation and the propensity to change stereotypes. Academy of Management Learning \& Education, 17, 62-78.

Alexandra, V. (2018b). The Roles of Social Complexity Belief and Perceived Contact Characteristics in Cultural Intelligence Development among Individuals Receiving Contact-Based Training. Journal of Cross-Cultural Psychology, 1-19. doi:10.1177/0022022118779743

Alshammari, M.T. (2020). Evaluation of Gamification in E-Learning Systems for Elementary School Students. TEM Journal, 9(2), 806-813.

Ang, S., Van Dyne, L., Koh, C., Ng, K.Y., Templer, K.J. et al. (2007). Cultural Intelligence: Its Measurement and Effects on Cultural Judgment and Decision Making, Cultural Adaptation and Task Performance. Management and Organization Review, 3(3), 335371. doi:10.1111/j.1740-8784.2007.00082.x

Ault, M., Craig-Hare, J., Frey, B., Ellis, J., \& Bulgren, J. (2015). The Effectiveness of Reason Racer, a Game Designed to Engage Middle School Students in Scientific Argumentation. Journal of Research on Technology in Education, 47(1), 21-40.

Azevedo, A., \& Shane, M.J. (2019). A new training program in developing cultural intelligence can also improve innovative work behavior and resilience: A longitudinal pilot study of graduate students and professional employees. The International Journal of Management Education, 17, 1-20. doi:https://doi.org/10.1016/j.ijme.2019.05.004

Bengoa, D.S., Ganassali, S., Kaufmann, H.R., Rajala, A., Trevisan, I., Berkel, J., et al. (2018). Shared experiences and awareness from learning in a student multicultural environment: measuring skills' development in intercultural intensive programs. Journal of International Education in Business, 11, 1-22. doi:10.1108/JIEB-01-2017-0006

Bicen, H., \& Aydogan, S.K. (2020). Gamification Education for Parents: Effects on Motivation and Communication. Revista de Cercetare si Interventie Sociala, 69, 176-193.

Bobanovic, M.K., \& Grzinic, J. (2019). Teaching Tourism Students with Cultural Intelligence. UTMS Journal of Economics, 10(1), 85-95.

Buchtel, E.E. (2014). Cultural sensitivity or cultural stereotyping? Positive and negative effects of a cultural psychology class. International Journal of Intercultural Relations : IJIR, 39, 40-52.

Bücker, J. J., \& Korzilius, H. (2015). Developing cultural intelligence: assessing the effect of the Ecotonos cultural simulation game for international business students. The International Journal of Human Resource Management, 26(15), 1995-2014. doi:10.1080/09585192.2015.1041759

Chao, M.M., Takeuchi, R., \& Farh, J.-L. (2017). Enhancing Cultural Intelligence: The Roles of Implicit Culture Beliefs and Adjustment. PERSONNEL PSYCHOLOGY, 70, 257-292. doi:10.1111/peps.12142

Chen, P.H. (2020). The Design of Applying Gamification in an Immersive Virtual Reality Virtual Laboratory for Powder-Bed Binder Jetting 3DP Training. Education Sciences, 10(172), 1-23.

Chen, Y.-C., Lu, Y.-L., \& Lien, C.-J. (2019). Learning environments with different levels of technological engagement: a comparison of game-based, video-based, and traditional instruction on students' learning. Interactive learning environment, 1-17. doi:10.1080/10494820.2019.1628781

Cheong, C., Filippou, J., \& Cheong, F. (2014). Towards the Gamification of Learning: Investigating Student Perceptions of Game Elements. Journal of Information Systems Education, 25(3), 233-244. 
Clawson, J.G. (2019). 11 Key characteristics of a global business leader. Retrieved November 10, 2020, from https://ideas.darden.virginia.edu/11-key-characteristics-of-aglobal-business-leader

Cruz, L., \& Penley, J. (2014). Too cool for school?: The effects of gamification in an advanced interdisciplinary course. Journal of Teaching and Learning with Technology, 3(2), 1-11. doi:10.14434/jotlt.v3n2.12991

Doney, I. (2019). Research into effective gamification features to inform e-learning design. Research in Learning Technology, 27, 1-17. doi:10.25304/rlt.v27.2093

Eisenberg, J., Lee, H.-J., Bruck, F., Brenner, B., Claes, M.-T., Mironski, J. et al. (2013). Can Business Schools Make Students Culturally Competent? Effects of CrossCultural Management Courses on Cultural Intelligence. Academy of Management Learning \& Education, 12(4), 603-621. doi:http://dx.doi.org/10.5465/amle.2012.0022

Erez, M., Lisak, A., Harush, R., Glikson, E., Nouri, R., \& Shokef, E. (2013). Going Global: Developing Management Students' Cultural Intelligence and Global Identity in Culturally Diverse Virtual Teams. Academy of Management Learning \& Education, 12(3), 330-355. doi:10.5465/amle.2012.0200

Fang, F., Schei, V., \& Selart, M. (2018). Hype or hope? A new look at the research on cultural intelligence. International Journal of Intercultural Relations, 66, 148-171. doi:https://doi.org/10.1016/j.ijintrel.2018.04.002

Fischer, R. (2011). Cross-cultural training effects on cultural essentialism beliefs and cultural intelligence. International Journal of Intercultural Relations, 35, 767-775. doi:10.1016/j.ijintrel.2011.08.005

Gertsen, M.C., \& Søderberg, A.M. (2010). Expatriate stories about cultural encounters - A narrative approach to cultural learning processes in multinational companies. Scandinavian Journal of Management 26, 248-257. doi:10.1016/j.scaman.2010.06.003

Goerlich, M. (2014). How Many Methods do We Need to Effectively Train Multicultural Teams? AU-GSB E-Journal, 7(1), 12-23.

Gómez-Carrasco, C.J., Monteagudo-Fernández, J., Moreno-Vera, J.R., \& Sainz-Gómez, M. (2019). Effects of a Gamification and Flipped-Classroom Program for Teachers in Training on Motivation and Learning Perception. Education Sciences, 9(4), 1-15.

Gustomo, A., Putranto, N. A., Ghazali, A., \& Nuraeni, S. (2018). Designing Effective Field Trip Activities to Develop Students' Cultural Intelligence. International Journal of Business and Society, 19(1), 195-208.

Illeris, K. (2009). Contemporary Theories of Learning Learning theorists ... in their own words. Oxon: Routledge.

Kay, D., \& Kibble, J. (2016). Learning theories 101: application to everyday teaching and scholarship. Advances in physiology education, 40, 17-25. doi:10.1152/advan.00132.2015

Khaleel, F., Ashaari, N., \& Wook, T. (2020). The impact of gamification on students learning engagement. International Journal of Electrical and Computer Engineering, 10(5), 4965-4972.

Kirste, L., \& Holtbrügge, D. (2019). Experiential Learning in the Digital Context: An Experimental Study of Online Cultural Intelligence Training. Journal of Teaching in International Business, 30(2), 147-174. doi: 10.1080/08975930.2019.1663775

Ko, B., Boswell, B., \& Yoon, S. (2015). Developing intercultural competence through global link experiences in physical education. Physical Education and Sport Pedagogy, 20(4), 366-380. doi:10.1080/17408989.2013.837441

Kolb, A., \& Kolb, D. (2009). Experiential learning theory: A dynamic, holistic approach to management learning, education and development. In S. Armstrong, \& C. Fukami, The SAGE handbook of management learning, education and development (pp. 42-68). London: SAGE. 
Kolb, D. (1984). Experiential Learning: Experience as the source of learning and development. Englewood Cliffs, NJ: Prentice Hall.

Kurpis, L.H., \& Hunter, J. (2016). Developing Students' Cultural Intelligence Through an Experiential Learning Activity: A Cross-Cultural Consumer Behavior Interview. Journal of Marketing Education, 1 -17. doi:10.1177/0273475316653337

Looyestyn, J., Kernot, J., Boshoff, K., Ryan, J., Edney, S., \& Maher, C. (2017). Does gamification increase engagement with online programs? A systematic review. PLoS One, 12(3), 1-19.

MacNab, B. (2012). An Experiential Approach to Cultural Intelligence Education. Journal of Management Education, 36(1), 66-94. doi:10.1177/1052562911412587

MacNab, B.R., \& Worthley, R. (2012). Individual characteristics as predictors of cultural intelligence development: The relevance of self-efficacy. International Journal of Intercultural Relations, 36, 62- 71. doi:10.1016/j.ijintrel.2010.12.001

MacNab, B.R., Brislin, R., \& Worthley, R. (2012). Experiential cultural intelligence development: context and individual attributes. The International Journal of Human Resource Management, 23(7), 1320-1341. doi: http://dx.doi.org/10.1080/09585192. 2011.581636

Marr, B. (2019). The 10 Vital Skills You Will Need For The Future Of Work. Retrieved November 10, 2020, from https://www.forbes.com/sites/bernardmarr/2019/04/29/the-10vital-skills-you-will-need-for-the-future-of-work/\#7ae47b493f5b

Mayer, C.-H., Viviers, R., Flotman, A.-P., \& Schneider-Stengel, D. (2016). Developing Senior Eccleasiastical Professionals' Emotional and Cultural Intelligence. Journal of Intercultural Communication(41), 1-32.

McClinton, R., \& Schaub, M. (2017). Developing Culturally Competent Colleagues: How One University Trains for Success in Diverse Organizations. Organization Development Journal, 35(4), 19-39.

McRae, N., Ramji, K., Lu, L., \& Lesperance, M. (2016). Developing global-ready graduates: The CANEU-COOP experience. Asia-Pacific Journal of Cooperative Education, 17(4), 377-386.

Minter, R. (2011). The Learning Theory Jungle. Journal of College Teaching and Learning, $8(6), 7-15$.

Ntokos, K. (2019). Swords and sorcery: a structural gamification framework for higher education using role-playing game elements. Research in Learning Technology, 27, 1-16.

Nygaard, C., Højlt, T., \& Hermansen, M. (2008). Learning-based curriculum development. High Educ, 55, 33-50. doi:10.1007/s10734-006-9036-2

Pierce, M., \& Longo, J. (2019). Incorporating Photovoice in the Marketing Curriculum to Increase Cultural Competence. Journal of Marketing Education, 1-11. doi:doi.org/10.1177/027347531987882

Pontes, H., Duarte, J., \& Pinheiro, P. (2020). An educational game to teach numbers in Brazilian Sign Language while having fun. Computers in Human Behavior, 107, 1-13.

Poondej, C., \& Lerdpornkulrat, T. (2019). Gamification in e-learning. Interactive Technology and Smart Education, 17(1), 56-66.

Presbitero, A., \& Toledano, L. (2017). Global team members' performance and the roles of cross-cultural training, cultural intelligence, and contact intensity: the case of global teams in IT offshoring sector. The International Journal of Human Resource Management, 1-21. doi:https://doi.org/10.1080/09585192.2017.1322118

Putz, L.-M., Hofbauer, F., \& Treiblmaier, H. (2020). Can gamification help to improve education? Findings from a longitudinal study. Computers in Human Behavior, 110, 1-12. doi:https://doi.org/10.1016/j.chb.2020.106392 
Ramsey, J., \& Lorenz, M. (2016). Exploring the Impact of Cross Cultural Management Education on Cultural Intelligence, Student Satisfaction, and Commitment. Academy of Management Learning \& Education, 15(1), 79-99. doi:http://dx.doi.org/10.5465/ amle.2014.0124

Rehg, M. T., Gundlach, M. J., \& Grigorian, R. A. (2012). Examining the influence of crosscultural training on cultural intelligence and specific self-efficacy. Cross Cultural Management: An International Journal, 19(2), 215 - 232. doi:http://dx.doi.org/10.1108/ 13527601211219892

Reichard, R., Dollwet, M., \& Louw-Potgieter, J. (2014). Development of Cross-Cultural Psychological Capital and Its Relationship with Cultural Intelligence and Ethnocentrism. Journal of Leadership \& Organizational Studies, 21(2), 150-164. doi:10.1177/1548051813515517

Reichard, R., Serrano, S., Condren, M., Wilder, N., Dollwet, M., \& Wang, W. (2015). Engagement in Cultural Trigger Events in the Development of Cultural Competence. Academy of Management Learning \& Education, 14(4), 461-481. doi: http://dx.doi.org/10.5465/amle.2013.0043

Rosenblatt, V., Worthley, R., \& Macnab, B. (2013). From Contact to Development in Experiential Cultural Intelligence Education: The Mediating Influence of Expectancy Disconfirmation. Academy of Management Learning \& Education, 12(3), 356-379. doi:http://dx.doi.org/10.5465/amle.2012.0199

Sahin, F., Gurbuz, S., \& Köksal, O. (2014). Cultural intelligence (CQ) in action: The effects of personality and international assignment on the development of CQ. International Journal of Intercultural Relations : IJIR, 39, 152-163.

Şanal, S., Akçay, A., Tutulmaz, M., \& Erdem, M. (2019). Application of Learning Theories in Online Instructional Environments and Materials: A Study for Developing a Set of Criteria. Bartın University Journal of Faculty of Education, 8(2), 707-732. doi:10.14686/buefad.528904

Saputro, R.E., Salam, S., Zakaria, M.H., \& Anwar, T. (2019). A gamification framework to enhance students' intrinsic motivation on MOOC. TELKOMNIKA, 17(1), 170-178.

Sheetal, D., Rao, S.A., \& Shah, J.S. (2018). Developing cultural intelligence: learning together with reciprocal mentoring. Human Resource Management International Digest, 26(3), 38-40.

Simões, J., Redondo, R., \& Vilas, A. (2013). A social gamification framework for a K-6 learning platform. Computers in Human Behavior, 29, 345-353.

Stewart, A.C., Wilson, C.E., \& Miles, A.K. (2014). Developing Ethically \& CulturallyIntelligent Leaders Through International Service Experiences. Journal of Leadership, Accountability and Ethics, 11(2), 115-127.

Stoian, C.E. (2020). Indirect vs. Direct Communication: Steps in Becoming Culturally Intelligent. Journal of Humanistic and Social Studies, 11(1), 93-102.

Sun, J. C.-Y., \& Hsieh, P.-H. (2018). Application of a Gamified Interactive Response System to Enhance the Intrinsic and Extrinsic Motivation, Student Engagement, and Attention of English Learners. Journal of Educational Technology \& Society, 21(3), 104-116.

Taras, V., Caprar, D.V., Rottig, D., Sarala, R.M., Zakaria, N., Zhao, F. et al. (2013). A Global Classroom? Evaluating the Effectiveness of Global Virtual Collaboration as a Teaching Tool in Management Education. Academy of Management Learning \& Education, 12(3), 414-435.

Thomas, D.C. (2006). Domain and Development of Cultural Intelligence: The Importance of Mindfulness. Group \& Organization Management, 31(1), 78-99. 
Thomas, D.C., Elron, E., Stahl, G., Ekelund, B.Z., Ravlin, E.C., Cerdin, J.L. et al. (2008). Cultural Intelligence: Domain and Assessment. International Journal of Cross Cultural Management, 8, 123-143. doi:10.1177/1470595808091787

Toda, A.M., Klock, A.C., Oliveira, W., Palomino, P.T., Rodrigues, L., Shi, L. et al. (2019). Analysing gamification elements in educational environments using an existing Gamification taxonomy. Smart Learning Environments, 6(1), 1-14.

Tsai, C.Y., Lin, H.S., \& Liu, S.C. (2019). The effect of pedagogical GAME model on students' PISA scientific competencies. Journal of Computer Assisted Learning, 1-11. doi:10.1111/jcal.12406

Tuleja, E.A. (2014). Developing Cultural Intelligence for Global Leadership Through Mindfulness. Journal of Teaching in International Business, 25(1), 5-24. doi:10.1080/08975930.2014.881275

Varela, O., \& Gatlin-Watts, R. (2014). The Development of the Global Manager: An Empirical Study on the role of Academic. Academy of Management Learning \& Education, 13(2), 187-207. doi:http://dx.doi.org/10.5465/amle.2012.0289

Walat, W. (2014). Cognitive Theories of Learning as the Basis for Didactic Metaprogramming. Informatol, 2(3), 145-149.

Wood, E., \& St. Peters, H. (2014). Short-term cross-cultural study tours: impact on cultural intelligence. The International Journal of Human Resource Management, 25(4), 558-570. doi:http://dx.doi.org/10.1080/09585192.2013.796315

Young, C.A., Badiah, H., \& Corsun, D.L. (2018). Developing Cultural Intelligence and Empathy through Diversified Mentoring Relationships. Journal of Management Education, 42(3), 319-346. doi:10.1177/1052562917710687 